\title{
OLHARES SOBRE O DESEJO SEXUAL
}

Maria do Carmo de Andrade-Silva ${ }^{1}$

\section{VIEWS ON SEXUAL DESIRE}

Resumo: A comunicação e o simbolismo transformaram o significado do impulso sexual nos humanos. A comunicação emocional e a linguagem simbólica, associadas às capacidades intelectuais e sociais, produzem uma alteração qualitativa, transformando o coito em relação. A sexualidade passa a poder ser ensinada, regulamentada, reprimida ou supervalorizada, possuindo fortes condicionantes sociais e encontrando-se inter-relacionada, às diversas experiências emocionais do desenvolvimento de cada um. O desejo sofre interferências múltiplas, advindas desde o período fetal, equilíbrio neuroendócrino, interações familiares, vínculos afetivo-sexuais, normas morais e religiosas, os interditos sociais, as interaçōes pessoais, a atração, o apaixonamento, o equilíbrio hormonal, o "outro", enfim, à saúde física, psíquica e social. Fatores que caracterizam e diferenciam o comportamento e o desejo sexual de cada um. Segundo Masters e Johnson (1997), não importa o quanto seja interessante tentar descrever um modelo prático dos vários componentes do desejo sexual, o que falta sempre é a sutileza que distingue a luxúria ou a paixão, das outras variedades de desejo sexual. O erotismo é um processo multifacetado, através do qual, nossa capacidade inata para a "tesão" foi moldada, suprimida ou supervalorizada. A moldagem erótica, ou a forma como se constituirão os conteúdos desejados, se fará através de mensagens claras ou sutis, conscientes ou inconscientes, conectadas às vivências afetivosexuais de cada um. O resultado de tudo isso irá esculpir a forma, a intensidade, os objetos e as possibilidades de manifestação do desejo (latente, fantasiado, expresso ou executado).

Palavras-chave: Desejo Sexual; interferências biopsicosociais.

Psicóloga. Mestre em Psicologia e Livre Docente em Sexualidade Humana. Coordenadora do Ambulatório de Sexologia do Instituto de Ginecologia da UFRJ.

e-mail:mariacarmoas@yahoo.com.br 
Abstract: The communication and symbolism transformed the sexual impulse meaning in the human being. The emotional communication and symbolic language together with the intellectual skills and social development produced a qualitative change: the transformation of sexual intercourse into sexual relation. Sexuality could then be taught, regulated, repressed or overvalued. It has also strong social conditionings and become interrelated to each individual emotional experience. The sexual desire is exposed to multiple interferences: - starting at the fetal period going to the neuroendocrinal balance - family relation - sexual and affection bonds - moral and religions rules - early personal sex experiences - sexual attraction - passion experiences - hormonal balance - and the partners. In summary the sexual desire is a consequence of the physical, psych, and the health. That is why it individual has its own sexual desire and behavior. According to Masters and Johnson (1997), in spite of the importance of establishing a practical model showing the sexual desire components it will never capture the subtle aspects that distinguish lust or passion from other sexual desire types. Eroticism is a multi faced process thought which our inborn sexual desire is reshaped suppressed or overvalued. The erotic model or the shape of the desire contents will be assembled though conscientious or non conscientious, subtle or explicit messages, connected to each individual affective/ sexual experiences. The end result of the above factors will shape, the form, the intensity, and the desire manifestations possibilities (latent, fantasized, explicit or consummated).

Keywords: Sexual desire; biological interferences; psychological interferences; sociological interferences

Durante muito tempo, a percepção quanto ao desejo sexual, esteve vinculada ao conceito de instinto, entendida como um mecanismo inato, tendo como objeto básico a manutenção da espécie. Um mecanismo evolutivo, adaptativo e vinculado ao ato biológico da reprodução. Na escala evolutiva das espécies animais, o comportamento sexual dos mamíferos, exceto o dos primatas, encontra-se regido pelo ciclo hormonal - e em especial vinculado às fêmeas através do "cio" ou estro. O estro é um fenômeno, que se caracteriza pela intensa presença de estrógeno, que se manifesta de forma cíclica, liberando óvulos - período de período fértil.

A ação desses hormônios também se faz incidir sobre o cérebro das fêmeas, fazendo com que se tornem receptivas, sexualmente aos machos. Pela ação hormonal, seus genitais tornam-se diferenciados e exalam um feromônio, que as tornam atraentes aos machos. Porém, quando se encontram em outro período do ciclo, repudiam a cópula e tornam-se pouco interessantes aos 
machos. As fêmeas não humanas escolhem seus machos, escolha que parece associada aos mecanismos de adaptação e seleção natural.

O jogo de conquista existe entre os animais, no "cio" das fêmeas, quando os machos se exibem mostram seu porte, força e competência e as fêmeas escolhem os melhores; em função de organismos mais saudáveis e adaptados. Assim, o jogo de conquista e atração, mesmo que mais vinculado aos mecanismos de preservação da espécie, têm início remoto na escala evolutiva e permanece de certo modo, ainda significante nos humanos. Só que os atributos, já não são vinculados somente a porte e força física.

Entre os humanos, as fêmeas escolhem como também são escolhidas, não só por atributos significantes à reprodução, mas também, pelas características sociais e psicológicas desejadas. Assim, à medida que se sobe na escala evolutiva, o controle do comportamento sexual, deixa de ter uma dominância essencialmente neuroendócrina, pois aos fatores biológicos se superpõem os psicológicos e os socioculturais.

Enquanto nos subprimatas, antes da puberdade, não se observa um padrão sexual característico do adulto, entre os primatas, alguns jogos de sua futura vida sexual, já são observados na infância. Nestes grupos, o desenvolvimento sócio-sexual infantil, já irá interferir no comportamento sexual adulto como argumentam Ford e Beach (1951) e Harlow (1965). Pode-se concluir, que se nos primatas as interferências do meio, já se manifestaram, muito mais ainda pode-se esperar que aconteça com humanos; produtos de um complexo mundo sociocultural. Além do fato de que, as fêmeas humanas, não apresentam as características típicas do estro e os contatos sexuais podem se dar durante todo o ciclo menstrual

No final do século XIX surge o termo Sexualidade, algo mais amplo e com limites menos definidos. Um sentido que envolve pessoas, onde o sexual, já não é somente o ato que une para reprodução, mas sim, algo vinculado ao desejo e a fantasia das sensações e do ato. Sexualidade nos leva a pensar em pulsões, emoções e, toda uma energia, que pode ser percebida através da interpretação de quem sente (um olhar, um sorriso, um toque, um cheiro, um tom de voz), algo vinculado aos sentidos e à representação simbólica.

Nos humanos, o desejo sexual foi associado a Eros (divindade grega representante da busca da expansão, da ânsia de amar, da união e de prazer), à libido, onde instinto sexual confunde-se com o impulso de vida e o desejo sexual é visto como a manifestação desse impulso. Em uma visão psicanalítica, as pulsões de vida e de morte (Eros e Thanatos), são a ambivalência maior do ser humano - pulsões em lutas constantes no sentido de prevalência. A 
pulsão de vida tem como representante o impulso sexual. Porém, o que se chama aqui de impulso sexual é uma força mais ampla, do que se convencionou chamar de desejo sexual. A preocupação está nos significados dos símbolos, na interpretação dos conteúdos por traz do impulso.

A comunicação e o simbolismo transformaram o significado do impulso sexual nos humanos. A comunicação emocional e a linguagem simbólica, associadas às capacidades intelectuais e sociais, produzem uma alteração qualitativa, transformando o coito em relação. A sexualidade passa a poder ser ensinada, regulamentada, reprimida ou supervalorizada, possuindo fortes condicionantes sociais e encontrando-se inter-relacionada, às diversas experiências emocionais do desenvolvimento de cada um.

Na espécie humana, o desejo sofre interferências múltiplas, advindas desde o período fetal, passando pelas interações familiares, os vínculos afetivosexuais, as normas morais e religiosas, os interditos sociais, as interações pessoais, a atração, o apaixonamento, o equilíbrio hormonal, o "outro", enfim, à saúde física, psíquica e social. Fatores que caracterizam e diferenciam o comportamento e o desejo sexual de cada um.

Em função destas múltiplas interferências, os impulsos que levam uma pessoa a uma atividade sexual, são muito variáveis. Envolvem-se com sexo, porém estão associados também, à busca de satisfação de alguma outra necessidade como: afeto, prazer, orgasmo, carinho, descarga de tensão, relaxamento, exercício de poder, etc. Até mesmo em outros momentos, a atividade sexual pode ser associada às obrigaçōes e rotinas, levando ao desprazer. Assim, dos encontros sexuais que se tem, serão poucos os que têm meta reprodutiva. Na maioria das vezes busca-se prazer e este, se traduz por uma percepção ampla e sem delineações claras.

\section{Interferências Familiares}

A maioria dos autores acredita que as primeiras experiências sensuais modelam o desejo sexual e são iniciadas na infância. Pode-se especular segundo Kaplan (1999), que o desejo de contato emocional e físico, de prazer mútuo, que a criança desfruta com seus pais, são estimulantes "eróticos leves"² e, por serem experiências de prazer, serão assimiladas nos códigos de memória sensual do indivíduo.

2 A continuidade detalhada das interferências familiares na estruturação dos elos eróticos leves poderá ser consultada em artigo, assim denominado, neste mesmo periódico, em seu número 2 (RBSH, vol. 18, n. 2, 2007). 


\section{Relativismo das normatizações sexuais}

É quase impossível falar de sexualidade e desejo sexual, sem refletir sobre os conteúdos morais, que permeiam a vida sexual dos seres humanos. Tais critérios levam sempre em consideração os discursos e práticas de cada época, variando da obediência a Deus, ao Rei e/ou às imposiçōes sociais, chegandose ao individualismo, marca do mundo moderno. Onde os dilemas entre os desejos e necessidades individuais têm como contraponto, os deveres morais, introduzindo-se, assim, o construto do homem psicológico.

Assim, entre a percepção do desejo sexual e o comportamento que se segue, existe um "tempo de reflexão", que aponta para as diversas formas de açōes possíveis. Como se tomando distância do que ocorre, para decidir a forma mais conveniente de expressão. Neste ponto, o ser humano não é prisioneiro do fato presente ou real, respondendo, sempre um pouco à frente e um tanto atrás de si mesmo, num processo de constante reflexão, onde se observa que a real avaliação do desejo, sempre estará comprometida.

Durante todo o tempo, em que sexo só podia existir, tendo como principal motivo a reprodução, a freqüência do ato deveria ser restrita e mecânica. $\mathrm{O}$ que acontecia com o corpo não deveria ter relação com o espírito. O prazer e/ou o erotismo "sujavam" o ato reprodutivo, contaminando o aspecto divino do surgimento de uma nova vida. Assim, quanto menor a freqüência de expressão de desejo, menos vínculos afetivos e de prazer eram desenvolvidos. Portanto, menos pecaminoso o ato e menor desrespeito a Deus.

No que se refere à expressão de desejo e/ou orgasmo, até o início do século $\mathrm{XX}$, as mulheres que os sentissem ou expressassem, eram consideradas portadoras de alguma psicopatologia, necessitando acompanhamento psiquiátrico. Com o passar dos anos, o desejo e o orgasmo feminino passaram a ser uma possibilidade e a partir dos anos de 1960, a atividade sexual voltou-se para as realizações de prazeres pessoais. A reprodução não mais possuía valor incondicionalmente positivo e, em função da nova ideologia vigente, o sexo devia ser prazeroso em si e não mais meta reprodutiva.

Nesta época, autores como Masters e Jonhson (1966-1970), descrevem um aprimorado ciclo da resposta sexual humana e, baseados nas fases deste ciclo tentam sistematizar e classificar a atividade sexual humana. Só que agora não se fala em patologias, desvios e perversões, mas sim em funcionalidade e disfuncionalidade. Todos devem ser funcionais sexualmente, exigências, opostas às do início do século XX. Kaplan (1977-1983) introduz 
mais um componente ao estudo do ciclo da resposta sexual, a percepção do desejo sexual. E nesta época o mundo já esperava das mulheres, expressão de desejo. Hoje, chegou-se à obrigação de tê-los. Não tê-los caracteriza uma disfunção - Transtorno do Desejo Sexual Hipoativo.

Com as novas exigências de expressões de erotismo feminino, surge a preocupação exacerbada, caso o desejo por sexo esteja diminuído, levando a conflitos, por não se estar adequado ao novo paradigma de época. O desejo contido, ainda característico do início do século XX, passou a ser exigido do casal contemporâneo. Se o desejo diminui, a preocupação torna-se evidente. "Será que o casamento acabou? Será que existe alguém interferindo na relação? Será que não sou mais erótica (o) para ele (a)? Será que víramos irmãos? Será que somos só pai e mãe? Nada de acomodação, se não tiver mais "tesão" tem que separar."

A masturbação, forma de auto-satisfação do desejo sexual, classificada anteriormente como pecado e/ou perversão, como vício, que poderia acarretar doenças, portanto prática punida e medicalizada (TANNAHILL, 1983); nos tempos atuais, passou a ser recomendada para a descoberta do corpo e do prazer, além de constituir-se em um dos itens de "sexo seguro," como forma de expressão do desejo sexual sem risco.

Com as mudanças pelas quais se está passando, racionalmente tem-se conseguido bons êxitos, porém emocionalmente, parece que não se consegue o mesmo feito. Encontram-se, na maioria das pessoas e dos casais, fortes conflitos entre o que "devem ser" e o que conseguem "sentir e fazer". Prensados entre valores tradicionais, com os quais foram criados e uma série de novas exigências, de como deveriam "ser" e comportar-se no mundo atual. Processo conflitivo que aponta para o fato, de que a pessoa encontra-se em luta com o seu próprio código de valores. Onde sentimentos de culpa, por não cumprir "seu dever", conduzem-nas a uma série de ambivalências - base de todo processo neurótico (ANDRADE-SILVA, 1999).

\section{As influências de uma história dicotômica em relação ao desejo}

Em nossa cultura a sexualidade de homens e mulheres possui padrões de comportamentos nitidamente diferenciados. A maioria destas diferenças encontra-se vinculada aos conceitos de masculinidade e feminilidade. Processos que ultrapassam os limites das diferenças biológicas e associam-se aos aspectos psicosociais, que lhes darão um colorido sexual especial e próprio de cada um. 
Desde o início das interações afetivas e sociais, a criança receberá influências de uma série de normas, e preferências, diferenciando-se claramente, o que se espera de um menino ou de uma menina em termos de papel sóciosexual ou papel de gênero. As regras de papéis de gênero fundamentam-se em um processo educacional que valoriza afeto, carinho, sensualidade e sedução, como expressão sexual feminina; enquanto que para o masculino espera-se força, objetividade, virilidade e expressão do desejo sexual definida.

Esse processo educacional dicotômico, que tem início na família, continua por uma série de diferentes expressões do "ser homem" e/ou "ser mulher", desenvolvidas através das interações com grupos de iguais, através da mídia, nas relaçōes escolares e por posturas religiosas; objetivando a internalização de um código típico para expressão de seus desejos sexuais masculinos ou femininos (ANDRADE-SILVA, 1999).

Essa dicotomia, é mais uma variável decisiva no que se refere à inibição ou expressão de impulsos sexuais, como constata Kaplan (1977), ao mencionar que em geral, o desejo sexual é mais variável na mulher do que no homem, sendo a expressão sexual feminina, também mais facilmente reprimida. Para os homens, o impulso é geralmente mais urgente e vinculado a conquistas e novidades. Kaplan (1999), ao se referir à inibição situacional do desejo, relata que a mulher pode experimentá-lo ao ser acariciada, mas pode perder o interesse quando: tais interaçôes encontram-se vinculadas a coito, ou à relações em que não estejam fazendo uso de contraceptivos, ou quando não estão "seguras" quanto ao significado da relação, ou após um parto, etc. Situações, em que em nível simbólico e/ou inconsciente, sinalizam risco, ansiedade ou perigo.

Logo após o nascimento, em função da própria anatomia e funcionamento do aparelho genital, onde nos bebês meninos a ereção se faz presente, é quase impossível que o pênis não seja notado e associado à virilidade, a algo dinâmico e com vida. Com isso, a relação do menino com seu pênis torna-se quase obrigatória, sendo mais aceita e até estimulada socialmente. Já a relação da menina com sua vulva é praticamente anulada, pois esta, além de escondida, não é sede de modificações visíveis ou relevância social.

Outro fator de diferenciação do desejo sexual masculino e feminino são as convicções, de que o desejo sexual do homem é algo instintivo e visível, necessitando ser descarregado, enquanto nas mulheres, não se observa tal premência. Esse tipo de crença, de que têm sempre que estar sexualmente interessados gera nos homens uma absurda cobrança, pois têm que "estar a 
fim" quando alguma situação sexual apresenta-se. Se não está interessado, algo vai mal, algo está errado. Deve estar doente.

O culto ao genital do homem se fez presente em várias culturas desde tempos remotos. Sua valorização encontra-se principalmente relacionada às divindades, fertilidade, magias, força, poder e virilidade. Por ser o pênis, seu representante dileto, todas as exigências feitas a ele, são repassadas ao pênis. Assim a perseguição de "competência", associada à manifestação do desejo sexual, é transferida ao pênis e sua funcionalidade.

Ainda hoje, alguns estereótipos compõem o imaginário masculino no que se refere à atividade sexual. Segundo Bernie Zilbergeld (1978), alguns destes ainda apresentam-se constantes e freqüentes, interferindo em suas vidas sexuais. Dados compatíveis com trabalhos de pesquisa de Andrade-Silva, Bueno e Paiva (1999) e Souto Maior e Andrade-Silva (2001), em amostragem com homens brasileiros, que apontam que principalmente as crenças de que: - A sexualidade masculina não precisa ser aprendida - Em sexo, como em tudo mais, a performance é o que vale e que - O homem sempre deseja e deve estar disposto ao sexo, se impõem na estruturação da personalidade masculina, obrigando-os à expressão de desejo constante.

Esta mesma função sexual, que é dever para o homem, foi durante muitos anos inexistente para a mulher. Tradicionalmente a elas, não coube ter desejos, mas apenas desejar, o que interessasse ao marido e submeter-se às expressōes dos desejos dele. Crença típica do final do século XIX, mas que ainda invadiu os primeiros 50 anos do século XX, acreditando-se, que as mulheres aceitavam o sexo por dever de casamento e por fazer parte de seu principal papel na natureza - ser esposa e mãe - seu objetivo de vida.

Em torno dos anos de 1950, encontra-se um novo conceito ideológico social, que de certo modo introduz uma "desculpa”, para a expressão sexual feminina, quando esta é fruto das "loucuras do apaixonamento". A sexualidade feminina pode então aparecer, antecedida pelo amor, que transformava a entrega física em doação ao amado - quando o desejo era pelo amor dele e não pelo sexo. Segundo Giese e Schmith (apud USSEL, 1980): o amor passou a ser o novo meio de repressão de seus impulsos sexuais.

Outro ponto significante, quanto à diferenciação do desejo sexual de rapazes e moças, desenvolve-se pela ação controladora da sociedade, durante a puberdade/adolescência. Quando do rapaz se exigirá, que ponha em prática a realização de seus desejos (heterossexuais, é claro), pois só assim será aceito no mundo dos "homens de verdade". Enquanto isso não acontece, vive a 
exigência, agora internalizada, de que "tem que ter vontade", "tem que ser capaz. Quanto às moças, ainda hoje, espera-se que aprendam a controlar seus desejos. A ele cabe insistir, quanto a ela cabe disfarçar, pelo menos no início, mas com cuidado para que não pareça uma negativa real. Só não pode parecer que está “dando mole demais". Assim, esse jogo de códigos e máscaras, exige controle consciente no lugar do simples "deixar fluir," exigindo equilíbrio fino e difícil.

Mais um ponto importante de diferenciação teve por base o sistema de crenças, baseado na concepção do "sexo frágill," o que reforça a dependência, gera temor de rejeição e impede o desenvolvimento da liberdade e atitudes mais sexuadas (FISHER, 1978).

No entanto, muita coisa tem se modificado e as novas exigências no comportamento sexual feminino, têm se tornado cada vez mais próximas, do padrão masculino. Após a liberdade advinda com a segurança dos contraceptivos orais, uma parte dos receios femininos dissipou-se, mas somente em parte, pois não se muda uma tradição em algumas poucas décadas. Exige-se hoje uma mulher sexuada, que tenha e expresse seus desejos sexuais, seduza e encante seu parceiro. Exige-se uma mulher experiente, que conheça seu corpo e saiba como alcançar e dar prazer através dele. Porém, as modificações racionais, quanto ao comportamento feminino, têm sido assimiladas a uma velocidade, que a estrutura afetivo-emocional, por vezes, não consegue acompanhar, pois estas têm raízes profundas.

Como ser experiente, em algo ainda pouco praticado e que, muitas vezes, ao ser vivido foi acompanhado de fantasmas, culpas, obrigações ou receios? Como ter desejos estáveis se durante tantos anos, não se pode desejar claramente? Foi preciso engolir e recalcar. Como ter vontade, de alguma coisa, que para várias, não foi agradável ou ao contrário, existia ou não; em função do atendimento aos desejos do "outro".

Porém, assim como no mundo das mulheres, podemos refletir sobre todas estas questões controladoras da expressão de desejos, no mundo dos homens. Lá a situação não é menos complicada. É simplesmente o reverso da moeda, caracterizada pela obrigação de ter que ter desejo. Atualmente, em um mundo de mulheres mais "liberadas", tais exigências têm sido mais pesadas, gerando conflitos. Pois homens, não aprenderam a dizer não a sexo quando este não é o seu desejo. E hoje, quando as mulheres podem fazer convites sexuais, por obrigação viril, se impõem aceitar, ainda que angustiados e sem real interesse sexual. 


\section{As orientações e o direcionamento do desejo sexual}

Apesar de na maioria das sociedades, o comportamento heterossexual ter sido a orientação sexual mais freqüente, atividades homossexuais ou bissexuais, foram constantes em alguns momentos da vida de alguns e/ou são, as mais freqüentes atitudes, em uma parcela de indivíduos em várias épocas e culturas.

As posições negativas da Igreja em relação à sexualidade não reprodutiva e em especial a homossexualidade, dominaram a ideologia ocidental, até que a medicina passou a regulamentar sobre essa temática no final do século XVIII e início do XIX. Então os comportamentos sexuais não reprodutivos, de pecados graves, passaram à posição de doenças, chegando ao início do século XX, diagnosticados como psicopatologias sexuais. Época em que a homossexualidade foi considerada uma doença congênita, advinda de falhas genéticas e predisposiçōes constitucionais do sistema nervoso (TANNAHILL, 1983).

Em 1974, a Associação Americana de Psiquiatria decidiu retirar o homossexualismo do rol das doenças psiquiátricas, pois estudos nesta época, concluíram que não existiam diferenças de instabilidade emocional ou doença psiquiátrica, que distinguissem homossexuais de heterossexuais (ANDRADE-SILVA, 2003).

No que se refere à estruturação das orientações sexuais, até o momento, uma série de estudos no campo da genética, das interferências hormonais, de estruturações cerebrais no período fetal, dos aspectos psicológicos e sociais, não chegaram a conclusões consideradas conclusivas. Aponta-se constantemente para o fato de que a estruturação da orientação sexual nos seres humanos é um intrincado emaranhado de influências interativas entre o biológico, psicológico e a sócio cultura, que dificultam os estudos na área.

Até o momento o que se conhece através de relatos de estudos em relação às orientações sexuais, é que existem indivíduos que apresentam uma direção de desejo sexual fortemente definida e fixada, enquanto em outros essa definição não se apresenta tão prevalente, podendo variar de forma constante ou esporádica. Portanto, pode-se observar muito mais do que uma simples dicotomia entre seres homossexuais e heterossexuais, apresentam-se amplas variaçōes entre as orientaçōes sexuais (homo-hetero e bi), as manifestações de seus desejos, fantasias e freqüência das atividades. Assim como suas características pessoais ou de personalidade, que se impõe em diferentes momentos e relacionamentos (KLEIN, 1990).

Como na relação homossexual, encontram-se pessoas com os mesmos papeis de gênero, observa-se neste mundo, que os padrões de papéis apresentam-se 
mais exacerbados, que quando diluídas em um par heterossexual. Observase que nos casais homossexuais masculinos, os desejos, a freqüência das relações, a valorização do pênis e uma rápida genitalização, são processos que ocorrerem freqüentemente, enquanto que nas interaçôes homossexuais femininas, a relação sexual mais imediata, com poucos vínculos e diretamente genitalizada, apresenta-se pouco freqüente.

\section{A intensidade das manifestações do desejo sexual}

Para Maslov (apud MORIN, 1996), temos constituído em nosso arsenal de memórias, momentos que de tão profundos e raros, podemos chamar de mágicos. Instantes inesquecíveis, onde estamos inteiramente vivos, expressando nossos "eus" mais verdadeiros e autênticos. Segundo o autor, tais processos podem acontecer por diversas formas (arrebatamento pela música, momento de comunhão com a natureza, processos místicos, etc.) Partindo dessa premissa, Morin (1996), associou que determinadas experiências afetivo-sexuais, também se constituem em momentos mágicos, produzindo sentimentos profundos de encontro consigo mesmo. Definiu este tipo de sensação, como experiência de pico erótico, inesquecíveis, de êxtase; onde os "eus" encontramse vinculados a real essência dos desejos sexuais.

Morin (ibid., 1996), afirma que tais lembranças, podem ser consideradas janelas para o entendimento da mente erótica de cada um. Janelas, que sinalizam para momentos especiais, onde realmente nos sentimos plenos. Segundo pesquisas do autor, tais experiências não são freqüentes, sendo para alguns até inexistentes.

Não necessariamente, o momento mágico erótico, encontra-se diretamente relacionado a uma experiência de "coito", fala-se de vivências de prazer erótico, e este pode ocorrer, em qualquer situação assim percebida como: beijos, intensa percepção de encontro com outro, acariciamentos; fatos que em determinado contexto e momento específico, foram apreendidos como mágicos para aquela pessoa.

Dados de pesquisa de Morin (ibid., 1996) apontam que parecem existir diferenças típicas entre o que é percebido como mágico no mundo das mulheres e no mundo dos homens. A maioria das mulheres, descreveu que em seus momentos mágicos: grandes romances, "climas", contexto e apaixonamento. Enquanto os homens associam-nos: à perfeição do corpo da parceira (o), sensualidade ou o que praticavam sexualmente. 
A relação interpessoal será básica, como ativadora ou inibidora, da percepção e da expressão do desejo sexual. É preciso que se tenha em mente, que existe um mobilizador, importante do desejo de cada um, que é o "outro". Pois a forma de ser e de se expressar, interfere na maneira de sentir e de se mostrar do "outro". Algumas pessoas funcionam como facilitadores da expressão do desejo do "outro", enquanto outros trabalham de forma consciente ou inconscientemente, a inibir o desejo do "um".

A comunicação não verbal intensifica e auxilia as interações humanas. Os sinais não verbais de expressão foram a base de processo interativo (mãe $\mathrm{x}$ bebê). Momentos onde a necessidade de entender o "outro", tornava-se o objeto primordial da relação. Uma interação de real identificação com os estados desejantes do "outro". Acredita-se, que esses momentos não verbais, deixem marcas no processo interativo, especialmente no que se refere às necessidades essenciais. Pois, são expressóes fortes e que de forma inequívoca, manifestam-se através das comunicaçōes não verbais do adulto. Expressōes que complementam as verbalizaçôes, ou ao contrário, denunciam contradiçôes, entre o que está sendo dito e o que é percebido.

Muitas vezes os desejos sexuais são denunciados pela direção ou a qualidade do olhar, pelas expressões faciais, os tons de voz, ou as posturas físicas; apontando para o fato de que o arsenal de muniçōes da comunicação não verbal, apesar das interferências intelectivas, não é de tão fácil submissão e controle. Tenta sobrepujá-los e escapar, lançando mão de nuances de detalhes primitivos iniciais, dando-se a perceber ao "outro", quando não pode ser completamente manifesto. Da mesma forma que se fazia entender, nas interações não verbais iniciais do processo do bebê com sua mãe.

O erotismo é um processo multifacetado, através do qual, nossa capacidade inata para a "tesão" foi moldada, suprimida ou supervalorizada. A moldagem erótica, ou a forma como se constituirão os conteúdos desejados, se fará através de mensagens claras ou sutis, conscientes ou inconscientes, conectadas às vivências afetivo-sexuais de cada um. O resultado de tudo isso irá esculpir a forma, a intensidade, os objetos e as possibilidades de manifestação do desejo (latente, fantasiado, expresso ou executado). Sabe-se que algumas qualidades como: beleza, inteligência, poder e saúde física, são características consideradas potenciais fatores de atração e desejo em diversas culturas. Porém, são conceitos relativos, pois parece que a questão, centra-se na forma como a realidade é percebida.

Alferes (1993), estudando a atração sexual refere que, às vezes a atração é produto de semelhanças, isto é as pessoas se atraem e desejam pessoas, que 
acreditam semelhantes a si próprias (em valores, classe social, capacidade intelectiva, beleza, etc.). Em outros momentos, a atração e o desejo, manifestam-se por complementaridade (deseja-se no “outro", aquilo que não se tem). Deseja-se a ele, por possui tal ou qual qualidade, que se admira e se fantasia que através da união com ele possa-se usufruí-la. Às vezes, a atração surge através de relações de trocas (um deseja no "outro" alguma qualidade que o "outro" possui). Um deseja o poder que o outro demonstra, enquanto o outro deseja a beleza que o "outro" tem. Nestes casos, estrutura-se uma relação de atrações e desejos mútuos, por potenciais trocas e complementaridades.

Em algumas estruturações de personalidade, o desejo encontra-se voltado para a proteção. Assim, uma figura parental compensatória das lacunas infantis, será o objeto desejado. Onde as figuras de atração, por simbolismos associados, precisarão ser fortes em termos de doação e proteção. Em outras constituições psicológicas, pessoas dominadoras precisam exercer seu poder, e este se encontra associado, às relações afetivo-sexuais frágeis e dependentes. Organizando-se uma atração por trocas e complementaridades. Alguns desejam o que não conseguem ter, o não atingível permanecendo em constante busca. Ainda outros vinculam o erotismo ao marginalizado, ao sujo, ao pecaminoso.

Assim, o processo de atração e de desejo sexual mistura-se, ora a conteúdos mais afetivos, ora a claros impulsos sexuais explícitos. Constituindo-se em uma teia complexa para o entendimento deste impulso. Onde, a estrutura de personalidade, desenvolve-se em um determinado ser, que trouxe predisposiçôes genéticas e constitucionais. Que vive em um meio ambiente afetivo específico e, que se encontra rodeado de crenças e valores, provenientes dos diversos meios socioculturais. Além de vivenciar em sua adolescência e idade adulta, relacionamentos sexuais com significados diferentes, complementando e complexificando, mais ainda, o emaranhado, que constitui os objetos sexuais desejados.

O desejo sexual parece ser produto de um estado de ativação cerebral, propiciado por fatores neuroendócrinos, onde estímulos sexuais advindos do meio-ambiente interno e externo são percebidos como despertadores sexuais. Neste sentido Levine (1988), acredita necessário diferenciar alguns aspectos: - Uma base neurofisiológica, onde o nível de ativação irá possibilitar a aparição da excitação sexual, processo que pode favorecer que os estímulos sexuais sejam percebidos de forma mais clara e relevante - Uma disposição emocional e cognitiva básica, que permitam ou não, que a pessoa possa sentirse aberta às sensações sexuais (estruturação da personalidade). - E estados 
transitórios como: stress, doenças, drogas, cansaço, depressão, apaixonamento, fantasias e estímulos sensoriais, que interferem no interesse por sexo.

Porém, algumas pessoas acabam vivenciando uma vida sexual descolorida, rotineira e sem qualquer vínculo, com o que para elas, seria a expressão de seus reais desejos sexuais. Nestes casos, relatam que já não têm tanta vontade têm até preguiça. Deixam para depois e, progressivamente, sentem-se desmotivadas - tudo tanto faz - ou pior, acabam por desenvolver algum tipo de disfunção sexual, justamente em função de viverem uma relação mecânica e sem "ouvidos," às necessidades dos reais impulsos de gratificação e prazer.

Outros permitem que a rotina das lutas do dia-a-dia, os engula e/ou sufoque como um polvo cheio de tentáculos, que progressivamente estreita mais as possibilidades de lazer e prazer, obrigando a que sexo, seja a última coisa a ser feita no dia. Momento em que as energias, praticamente já foram sugadas e o que restou, "só dá pro gasto". Para algo rápido, antes que o sono domine. Mas, que permita a louca sensação de dever cumprido, o engano de acreditarse, que apesar de tudo, ainda continua-se vivo, sexuado e "normal".

Cuidar da vida sexual, assim como se cuida e investe, em tantas outras coisas; pode parecer estranho para uma grande parcela de pessoas, especialmente para aquelas, que acreditam a vida sexual como simples instinto biológico. Porém, há muito isso não é tão simples. A sexualidade é vivenciada em um meio social, portanto preparar-se, poderia acontecer tão naturalmente, como para as tantas outras ocasiōes do cotidiano.

O interesse em sexo, na maioria das vezes é lazer, prazer, afeto, "brinquedo de gente grande”. Portanto, só se precisa querer e, para isso, não se tem regra fixa, ou freqüência preestabelecida. Faz-se porque é bom, brinca-se quando se quer, daquilo que é bom e com quem se deseja, sem "ter que", sem "deve ser".

A rotina, também pode tornar-se monótona por melhor que seja. Quebrar a rotina é necessário. Por que não fazer do encontro sexual um programa? Não é incomum, que casais em férias, ou em um fim de semana em local aprazível, percebam um renascer de seus impulsos sexuais. O que mudou? Mudou a rotina.

Não ter vontade de fazer sexo às vezes, é semelhante a não ter vontade de ir à praia, por mais que se goste muito e se tenha o hábito de fazê-lo. Porém em alguns momentos, se está cansado, estressado, preocupado, ou simplesmente desinteressado, e isto é perfeitamente "normal" ou aceito. Porém para sexo, 
não pode acontecer, pois a percepção é de que algo deve estar errado, não se pode não ter desejo.

Para Master, Jonhson, e Kolodny (1997), o desejo sexual sofre interferências físicas, psicológicas e sociais. Componentes que interatuam de forma dinâmica, aumentando ou diminuindo suas manifestaçóes. Tal processo poderia ser associado a um modelo vetor matemático, ao se imaginar os vários fatores, (+) positivos e (-) negativos como tridimensionais, onde o tempo comporia a terceira dimensão. Pode-se perceber que embora o desejo sexual, seja a soma de todos esses elementos, várias combinações e alteraçōes de intensidade de algum vetor, altera significativamente o desejo. Acrescenta-se ainda, que tanto os indivíduos como os momentos, são mecanismos dinâmicos, o que propicia variações ainda maiores. Segundo os autores, não importa o quanto seja interessante tentar descrever um modelo prático dos vários componentes do desejo sexual, o que falta é a sutileza que distingue a luxúria ou a paixão, das outras variedades de desejo sexual.

Iversen, Kupfermann e Kandel (2003) afirmam que, como todos os controles fisiológicos da motivação, também o desejo sexual encontra-se vinculado a um processo dual (excitatório e inibitório). Quando não se tem sexo há algum tempo e uma possibilidade interessante apresenta-se, é provável que se perceba um forte impulso para tal. No entanto se alguma situação de risco, símbolo de perigo surgir, na maioria das vezes, esta se sobrepõe ao desejo bloqueandoo. Tal ordenamento hierárquico é exercido, em função do antigo mecanismo de adaptação e sobrevivência das espécies. E mesmo hoje, quando os riscos não estão vinculados às lutas por sobrevivência, as emoçōes de “tensão", encontram prioridade de reação. Damásio (apud IVERSEN, KUPFERMANN e KENDAL, 2003), menciona que quando pensamos sobre as possíveis conseqüências de um comportamento, a memória dos estados emocionais (experiências viscerais), de situações semelhantes, propiciam informações para a avaliação atual (intuição). A memória pode ativar projeções ascendentes noradrenérgicas ou colinérgicas do tronco encefálico e do prosencéfalo basal, que ativam o córtex e replicam a sensação consciente do estado emocional relembrado.

Não existe até o momento, uma fórmula específica para avaliação da "normalidade" com que as percepçōes do desejo devam manifestar-se, e muitas vezes, essas aferições têm sido efetivadas através da freqüência das relações. No entanto, freqüência não é sinônimo de desejo. O problema é tentar quantificar algo tão subjetivo como é o desejo. Âs vezes as pessoas dizem que têm vontade de ter vontade ou que estão com vontade, mas não têm vontade. Confundindo-se a vontade racional com a percepção do impulso. 
Kaplan (1999) propõe que para o entendimento das manifestações do desejo sexual, é preciso que se leve em consideração, uma série de variantes etiológicas (físicas, psíquicas e sócio culturais), que podem interferir na intensidade com que o desejo manifesta-se. Segundo a autora, pode-se dividir as manifestações do impulso sexual, em seis categorias de um contínuo: desejo sexual hiperativo, normal elevado, normal baixo, hipoativo, hipoativo grave, aversão ou evitação fóbica.

Para ela os problemas de desejo, são resultantes de múltiplos determinantes, que podem operar em níveis mais superficiais (imediatos) ou em níveis profundos da estrutura de personalidade (intrapsiquicos). Inclusive, em alguns casos interatuando uns sobre os outros, bloqueando as percepçóes de desejo. As causas imediatas são caracterizadas, por ansiedade, sensaçōes desagradáveis e pensamentos negativos, quanto ao que está ocorrendo ou ao que representam. Enquanto as causas intrapsíquicas, caracterizam-se por interações neuróticas com raízes na infância e, na maioria das vezes, inacessíveis à consciência imediata.

No entanto, mesmo nas etiologias imediatas, que em termos estruturais relacionam-se a focalização negativa à percepção sexual, na maioria das vezes, tais crenças, não se encontram suscetíveis à percepção consciente, ou simplesmente, a pessoa não acredita e não relaciona que tal fator, possa interferir em seus impulsos sexuais. Mencionam que não sabem por que não têm desejo. Para a maioria destas pessoas, só através de alguma forma terapêutica, consegue-se perceber que: o parceiro não é semelhante à fantasia sexual que tem, a relação é hostil em outras áreas e esta é transportada para a área sexual, os jogos sexuais não são adequados, a pessoa está vivendo momentos depressivos, estressantes etc. Porém, não existe percepção, de que tais fatos tenham conexão com a sua falta de desejo sexual, por mais incrível que pareça.

Em pesquisa realizada por Abdo (2004) com 2835 indivíduos de nosso país, a disfunção sexual mais referida pela população feminina foi a falta de desejo sexual (34\%), seguida pela disfunção orgásmica (29\%). Padrão de referência bastante similar ao encontrado por estudo de Andrade-Silva (2003) em queixas de população clínica, que freqüenta o Ambulatório de Sexologia do Instituto de Ginecologia da Universidade Federal do Rio de Janeiro. Onde inclusive, a associação das duas disfunçōes (anorgasmia e transtorno de desejo), apresentou-se simultânea e interligada frequentemente.

Várias são as causas psicológicas e sociais, que podem levar um indivíduo a inibir completamente, ou sentir seus impulsos eróticos fortemente diminuídos, 
exigindo do terapeuta, formação ampla na área para que possa efetivar um diagnóstico diferencial adequado ao problema apresentado. Como sugere Kaplan (1983) é importante se afastar um problema psiquiátrico e posteriormente verificar, se o problema sexual tem base primordialmente orgânica ou psicológica, se é intrapessoal ou interpessoal diádico.

\section{Referências bibliográficas}

ABDO, C. H. N. (2004). Estudo da Vida Sexual do Brasileiro. São Paulo: Bregantini, 2004

ALFERES, V. R. Atração interpessoal, sexualidade e relações íntimas em psicologia social. In: VALA, J. E MONTEIRO, M. B. (Org.). Psicologia Social. Lisboa: Fundação Calouste Gultbenkian, 1993.

ANDRADE-SILVA, M. C.(1999). Formação e desenvolvimento da identidade sexual ou identidade de gênero. In: RIBEIRO, M. (org.). O Prazer e o Pensar. São Paulo: Gente, 1999.

ANDRADE-SILVA, M.C.; BUENO, A.P.; PAIVA, J.S. A. B. U. O. Crenças e Estereótipos sobre a Sexualidade Humana Masculina. In: Scientia Sexualis, Revista do Mestrado em Sexologia da Universidade Gama Filho, Vol.5, no. 1, (69-104)., 1999.

ANDRADE-SILVA, M.C. Terapia Sexual e Inclusão Social. Revista Brasileira de Sexualidade Humana da SBRASH. Vol.14, nº. 2 (2738), 2003.

ANDRADE-SILVA, M.C. Moral e Ética da Sexualidade. Anais do VII Congresso Brasileiro de Sexualidade Humana da SBRASH. (161-164). Rio de Janeiro, 2001.

FISHER, S. O orgasmo da mulher. São Paulo: Monde, 1978.

FORD e BEACH, F.A. Patterns of sexual behavior. USA: Harper e Broth Publishers, 1951.

HARLOW, H. F. Sexual behavior in rhesus monkey. In: BEACH, F. A.

Ed. Sex and Behavior. New York: John Willey e Sons, 1965.

IVERSEN.S.; KUPFERMANN, I.; KANDEL, E. R.(2003). Sentimentos e Emoções. In: KANDEL, E. R.; SCHWARTZ, J. H.; JESSELL, T. M. (Eds.). Princípios da Neurociência. São Paulo: Manole, 2003. KAPLAN, H. S. The evaluation of sexual disorders: Psychological and Medical Aspects. New York: Brunner Mazel Publishers, 1983. A nova terapia do sexo. Rio de Janeiro: Nova Fronteira, vol. 2, 1977.

. A Nova Terapia do Sexo: O Desejo Sexual - vol. 2. Rio de Janeiro: Nova Fronteira, 1983. 
Transtornos do desejo sexual. Porto Alegre: Artimed, 1999.

KLEIN, F. The need to view sexual orientation as a multivariable dynamic process: A theoretical perspective. In: WHIRTER, D.P.M.C.; SANDERS, S.A; REINISCH, J.M. (eds.), Homosexuality/Heteresexuality: Cmcepts of Sexual Orientation. New York: Oxford University Press, 1990.

LEVINE, S.B. Intrapsychic and individual aspects of sexual desire. In:. LEIBLUN, S.R.; ROSEN, R.C..(eds.). Sexual Desire Disorders. New York: Guilford Press, 1988.

MASTERS, H. W. \& JOHNSON, V. E. Conduta sexual humana. Rio de Janeiro: Civilização Brasileira, 1966.

MASTERS, H. W. \& JOHNSON, V. E. Incompetência sexual - suas causas e tratamentos. Rio de Janeiro: Civilização Brasileira, 1970.

MASTERS, H. W.; JOHNSON, V. \& KOLODNY, R. Heterossexualidade. Rio de Janeiro: Bertrand Brasil, 1997.

MORIN, J. A Mente Erótica. Descobrindo as fontes internas da paixão e satisfação sexuais. Rio de janeiro: Rocco, 1996.

SOUTTO-MAYOR, A. \& ANDRADE-SILVA, M.C. Principais Estereótipos sobre a Sexualidade Masculina. In: Scientia Sexualis, Rev. do Mestrado em Sexologia da U.G.F. Vol.7 no.3, (95-108), 2001.

TANNAHILL, R. O sexo na história. Rio de Janeiro: Francisco Alves, 1983. USSEL, J. V. Repressão sexual. Rio de Janeiro: Campus, 1980.

ZILBERGELD, B. Male sexuality. New York: Bantam Books, 1978. 